\title{
Sustainability in Manufacturing Facility Location Decisions: Comparison of Existing Approaches
}

\author{
Uwe Dombrowski, Christoph Riechel, and Hannes Döring \\ Institute for Advanced Industrial Management, \\ Technische Universität Braunschweig, Braunschweig, Germany \\ $\{$ u.dombrowski, c.riechel, h.doering\}@tu-bs.de
}

\begin{abstract}
Facility location decisions concern the positioning of production facilities regarding international, national, regional or local level. Indicator sets and methods for the support of such decisions traditionally focus economic aspects. However, approaches for solving the facility location problem by taking into account the three pillars of sustainability, namely social, ecological and economic aspects, are still rare. This paper complements existing reviews by a structured analysis of established indicator sets and evaluation methods for facility locations in comparison to approaches focusing sustainability aspects.
\end{abstract}

Keywords: Facility location, manufacturing, sustainability.

\section{$1 \quad$ Introduction}

Facility location decisions concern the positioning of production facilities regarding international, national, regional or local level [1], [2]. In a globalized world being characterized by international markets, competitors and supply chains, the importance of decisions on facility locations increases. [3] Indicator sets and methods for the support of facility location decisions traditionally focus economic aspects resulting from distances to customers and suppliers. Moreover, aspects like skills and knowledge have been addressed for several years. [1] Since the Brundtland Commission defined the terminology of sustainable development [4], decisions in companies increasingly consider sustainability aspects [1]. However, specific approaches for solving the facility location problem by focusing the three pillars of sustainability, namely social, ecological and economic aspects, are still rare. Accordingly, to obtain competitiveness, existing methods and indicator sets have to be analyzed and extended by sustainability metrics where necessary. Recently, two related reviews were published. Terouhid et al. reviewed location studies, which concentrate on sustainability [2]. Chen et al. took a broader view. They also reviewed papers focusing sustainability assessment in supply chains and production networks [1].

This paper complements these reviews by a structured analysis of established conventional indicator sets and evaluation methods for facility locations in comparison to new approaches focusing sustainability aspects. Thereby, it aims at the identification of potentials as well as need for improvement in existing concepts. 


\section{Methods and Materials}

To provide a structured comparison of facility location planning approaches, the review was divided into two parts. Firstly, evaluation criteria were derived from previous reviews in the area of sustainability science and sustainable facility location or factory planning. Secondly, established conventional approaches and sustainability oriented concepts for facility location planning were compared against the criteria. In this chapter, the review process and the developed evaluation criteria are summarized.

\subsection{Review Process}

Within this paper, two kinds of approaches were reviewed. On the one hand, sustainability oriented approaches, explicitly focusing the facility location problem, were chosen from the review of Chen et al. [1]. The keywords factory location problem and sustainable factory location problem and sustainable factory location assessment were used for an additional search in Scopus and Google Scholar to identify approaches from the last 20 years focusing sustainable factory location. On the other hand, broadly used conventional approaches regarding the facility location problem without focusing sustainability were investigated. Within the conventional methods and indicator sets all approaches that have been published by established German institutes with research focus on facility planning within the past 30 years were analyzed. The conventional approaches with regard to the facility location problem were compared. Thereof, approaches with unique features were recognized further. These approaches were representatively analyzed for similar concepts of other German institutes. The sustainability oriented and conventional Indicator sets and methods were then compared regarding the criteria defined in the following section 2.2. For the assessment, a tripartite scale was used. The approaches were evaluated against the criteria by differentiating full fulfillment, partial fulfillment and non-fulfillment.

\subsection{Evaluation Criteria}

The evaluation criteria used in this paper were derived from papers found in databases like Scopus, Science Direct, Google Scholar dealing with the comparison or evaluation of sustainability assessment methods or indicators. The research was based on the keywords facility location, facility location meta review and facility location sustainability. Just studies from the last 5 years were used to ensure state of the art. The set of criteria was defined in three steps. Firstly, more than 90 criteria were obtained from related papers. Secondly, criteria with the same content were consolidated. Thirdly, each criterion was checked regarding its relevance for the evaluation of indicator sets and methods in the area of facility location decisions by experts. For instance, criteria focusing the quality of single indicators were excluded as they cannot be used for the evaluation of complete indicator sets. Within this step, aspects which were not named by other authors but show relevance for the facility location problem were added or changes within the scope of criteria were conducted. 
The criteria were derived from six recent journal articles with partly different scopes. General demands on sustainability assessment were chosen from a metareview, which structured reviews on sustainability assessment [5]. Criteria being more specific to the assessment of indicator sets were derived from works, which formulated requirements on indicators [6], [7]. To define criteria that are specific to the evaluation of sustainability assessment for factories and facility location decisions, criteria used in respective reviews were taken into account [2], [8]. In addition, to support a review focusing on specific problems within sustainable facility location, research gaps, which were identified within the review of Chen and colleagues [1], were taken over into the criteria list. A set of 14 evaluation criteria resulted from the selection. These criteria are shown in Table 1. In the following, their content is summed up.

Completeness of scope: As shown in Table 1, researchers commonly discuss three pillars of sustainability when structuring sustainability assessment methods and indicators. Some authors refer to the Wuppertal sustainable development indicator framework and the (UN) Commission on Sustainable Development. These consider a fourth dimension, namely institutional indicators [6], [9], [10], [11]. Within this work, institutional sustainability is considered as the level at which sustainability aspects from the three pillars are integratively anchored in the legislation of a location.

Strategicity: Sala et al. identified a central relevance of Life Cycle Thinking for sustainability assessment when analyzing comparative studies after 2005 [5]. Terouhid et al. also defined a criterion to evaluate, if methods are life cycle oriented [2]. Within this work, the integration of up- and downstream effects along the product life cycle and supply chain is termed as life cycle orientation. [5] Following Strohm and Ulich, the criteria of a holistic view is used to evaluate, if indicator sets and methods consider people, technology and organization and their interactions [12].

Database: Applicability is used as central criterion for sustainability assessment and is often dependent on data availability [5], [6], [7]. Accordingly, data availability was selected as criterion within this work. In addition, indicator sets and assessment methods are compared regarding the transparency of data sources as well as the transparency of data gathering within the methodological frame.

Indexes and Indicators: Different papers, which were analyzed, support the evaluation of single indicators [6], [7]. Aspects like reliability or relevance are used as criteria. However, within this work, whole indicator sets were compared. Based on the paper of Singh et al. the level of objectivity and quantification were chosen as criteria [6]. They were used to evaluate a general tendency within analyzed indicator sets.

Methodology: The fifth criteria section focuses methodological aspects. Interdisciplinarity was used to evaluate, if perspectives of different functional experts are considered in indicator sets and methods. The grade of generic applicability and flexibility describes if approaches are usable for different sectors. The question, if approaches take a proactive view by including planned improvement into the assessment was addressed as well. The integratedness describes if side effects between the pillars of sustainability are considered. Another criterion, identified by Sala et al., is if alternative scenarios are taken into account [5]. Within this work, this aspect is described as inclusion of external future influences. Finally, the existence of normalization and scaling in indicator sets and the participation of stakeholders were evaluated. 
Table 1. Selected criteria for the evaluation of indicator sets and assessment methods

\begin{tabular}{|c|c|c|c|c|c|c|}
\hline \multicolumn{7}{|l|}{ Authors / Source } \\
\hline Focus / Topic & 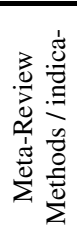 & 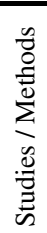 & 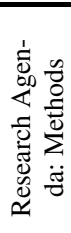 & 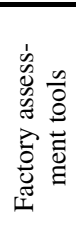 & 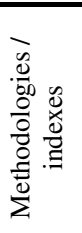 & 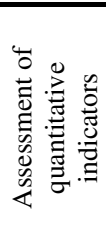 \\
\hline \multicolumn{7}{|l|}{ Completeness of scope } \\
\hline $\begin{array}{l}\text { Dimensions of Sustainability } \\
\text { (social, ecological, economic) }\end{array}$ & $\mathrm{X}$ & $\mathrm{X}$ & $X$ & $X$ & $X$ & \\
\hline Strategicity & $\mathrm{X}$ & & & & & \\
\hline Holistic view & $\mathrm{X}$ & & & & & \\
\hline Life cycle oriented approach & $\mathrm{X}$ & $\mathrm{X}$ & & & & \\
\hline \multicolumn{7}{|l|}{ Database } \\
\hline Data availability & $\mathrm{X}$ & & & & $\mathrm{X}$ & $\mathrm{X}$ \\
\hline Transparency & $\mathrm{X}$ & & & & & \\
\hline \multicolumn{7}{|l|}{ Indexes/Indicators } \\
\hline Quantitative Level & & & & & $\mathrm{X}$ & \\
\hline Level of objectivity & & & & & $\mathrm{X}$ & \\
\hline \multicolumn{7}{|l|}{ Methodology } \\
\hline Interdisciplinarity & & $\mathrm{X}$ & & & & \\
\hline Generic applicability / flexibility & & & & $\mathrm{X}$ & $\mathrm{X}$ & \\
\hline Proactive approach & & & $\mathrm{X}$ & & & \\
\hline Integratedness & $\mathrm{X}$ & & & & & \\
\hline Alternative scenarios / Future & $\mathrm{X}$ & & & & & \\
\hline Scaling / Normalization & & & & & $\mathrm{X}$ & \\
\hline Participation of stakeholders & $\mathrm{X}$ & & & & & \\
\hline
\end{tabular}

\section{Results}

Based on the derived evaluation criteria, conventional indicator sets and evaluation methods for facility locations were compared to approaches focusing sustainability aspects. The following approaches were selected from a holistic literature review.

Kettner et al. follow a structured approach. It starts with the identification of external and internal factors. These sets define company specific characterizations of the descriptive variables for the location factors. [14] Taking into account the corporate objective, the location problem is then narrowed to a requirement profile for the location to be searched. Using the value benefit analysis (VBA), the indicator set is assessed. The assessment is team based. [14]

The approach of Aggteleky et al. is characterized by the recognition of almost all areas of business activity, operational processes and the future possibility for location development. Thus, sustainably aspects with scope on the social and ecological influences are included. The assessment is based on the VBA as well. [15]

Wiendahl et al. focus the location choice by a goal-setting process recognizing technologies, market situation and environment as external factors. As internal factors 
strategic objectives and vulnerabilities are taken into account. Vulnerabilities are, for example, lack of logistic performance or capacity bottlenecks. The approach proceeds stepwise, following different levels of assessment. [16]

Pawellek et al. differentiate general location factors, function-related factors and global factors. Global factors are, for instance, political, economic and socio-cultural factors. Thereby, they include aspects of sustainability into their indicator set. Similarly to Kettner, Aggteleky, and Wiendahl, they use a variation of the VBA. [17]

Egan and Jones present an assessment tool, which focuses the evaluation of sustainability at company level. This tool can be applied to facility location problems. The main innovation of their approach is the transfer of a fuzzy logic to the sustainable facility location problem. [18]

Corbiere-Nicollier and an aerospace manufacturer developed an approach, which indicates economic, environmental and social aspects. The approach recognizes sustainability and traditional performance indicators of a facility simultaneously. [19]

Reich-Weiser and Dornfeld adopt the location problem by aspects of sustainability. They focus greenhouse gas emission and water consumption. To assess tradeoffs between costs, flexibility and environment they use a quantitative model and life cycle analysis. This model shows direct and indirect effects of transportation and facility location. [20]

The presented approaches with their indicator sets and methods were evaluated in a team of experts, being experienced in factory location problems and sustainable factory approaches. The evaluation was based on the tripartite scale shown in Table 2. The "plus" shows a full fulfillment, the "o" a partially fulfillment and the "minus" a nonfulfillment. In the following the results of the assessment are summarized.

Dimension of Sustainability: None of the indicator sets covers the whole spectrum of sustainability. The indicator sets are mostly specialized on one or two dimensions. The social and institutional dimension of sustainability is not recognized at all.

Strategicity: Strategicity aspects are more or less recognized in all approaches. The scope on life cycle effects by using for example a life cycle assessment method or tool can only be found within the new approaches focusing on sustainability aspects.

Database: The database-criteria are generally fulfilled by all sets and methods. However, the availability of data is a problem in some countries. A similar result is identified for the transparency-criterion. The origin of the database and thus their transparency and integrity is recognized, but does not meet the full extent.

Indexes/Indicators: Regarding indicators, the levels of objectivity and quantification were evaluated. Conventional approaches of location finding use objective and subjective assessment indicators in their sets. In particular, complex issues are subjectively evaluated by experts. However, the sustainability-oriented approaches based on mathematical models use objective and quantitative criteria.

Methodology: The conventional indicator sets and evaluation methods for facility locations are based on a static environment and do not sufficiently take into account future influences. This applies to the factory itself, but mostly the future development of its environment. Also, the opportunities for a proactive development of locations and their surroundings are not included in methodologies. Another potential of the classical approaches can be identified in the consideration of side effects. In this context, sustainability-oriented approaches based on mathematical models have an advantage. They analyze this interaction by multi-criteria analysis. 
Table 2. Results of the evaluation process

\begin{tabular}{|c|c|c|c|c|c|c|c|c|c|}
\hline \multirow{4}{*}{$\begin{array}{l}\text { Dimension of } \\
\text { Sustainability }\end{array}$} & Social & - & - & - & - & $\mathrm{o}$ & + & + & - \\
\hline & Ecological & $\mathrm{o}$ & + & $\mathrm{O}$ & - & - & + & + & + \\
\hline & Economical & $\mathrm{o}$ & + & - & o & $\mathrm{o}$ & + & + & + \\
\hline & Institutional & - & + & $\mathrm{O}$ & - & - & - & - & - \\
\hline \multirow[t]{2}{*}{ Strategicity } & Holistic View & $\mathrm{o}$ & + & $\mathrm{O}$ & - & - & + & $\mathrm{O}$ & $\mathrm{O}$ \\
\hline & Life Cycle Orientation & - & $\mathrm{O}$ & - & - & $\mathrm{O}$ & $\mathrm{O}$ & $\mathrm{o}$ & + \\
\hline \multirow[t]{2}{*}{ Database } & Data availability & $\mathrm{o}$ & $\mathrm{o}$ & $\mathrm{O}$ & $\mathrm{O}$ & $\mathrm{o}$ & + & + & + \\
\hline & Transparency & $\mathrm{o}$ & $\mathrm{o}$ & $\mathrm{o}$ & $\mathrm{O}$ & $\mathrm{O}$ & $\mathrm{o}$ & $\mathrm{o}$ & $\mathrm{O}$ \\
\hline \multirow{2}{*}{$\begin{array}{l}\text { Indexes/ } \\
\text { Indicators }\end{array}$} & Quantitative level & o & $\mathrm{o}$ & $\mathrm{o}$ & $\mathrm{o}$ & $\mathrm{o}$ & + & + & + \\
\hline & Level ofobjectivity & $\mathrm{O}$ & $\mathrm{o}$ & $\mathrm{O}$ & $\mathrm{o}$ & $\mathrm{o}$ & - & - & + \\
\hline \multirow[t]{7}{*}{ Methodology } & Interdisciplinary & + & + & + & + & + & - & - & - \\
\hline & Generic applicability & + & + & + & + & + & + & + & + \\
\hline & Proactive & - & - & - & - & - & - & - & $\mathrm{O}$ \\
\hline & Side Effects & - & - & - & - & - & + & + & + \\
\hline & Future influences & - & - & - & - & - & - & - & + \\
\hline & Scaling / Normalization & + & + & + & + & + & + & + & + \\
\hline & Participation & o & o & o & o & o & - & - & - \\
\hline
\end{tabular}

\section{Discussion}

In the following, the results of the evaluation are discussed and summarized. Conventional indicator sets and evaluation methods for facility locations mainly use qualitative assessment indicators. This creates benefits for the participation and facilitates the evaluation of complex interdependencies. However, the results depend on the composition of the planning team. This includes a risk of incorrect decisions. It was also determined that present assessment indicators are developed under the assumption of a static or slowly changing environment and a low level of complexity. If these assumptions reflect the current conditions of a volatile environment is questionable.

The new approaches with focus on sustainability concentrate on the quantification of location indicators. A major advantage of these approaches is the use of mathematical models with quantitative results for the defined conditions. However, the question is, if mathematical models are applicable to the full complexity of the factory location problem. The life cycle orientation and the consideration of future developments offer potential for future location planning, to sufficiently answering questions in extent.

In conclusion, the reviewed assessment sets and methods need to be combined. The goal of this combination is to minimize the risk and to increase the quality of the factory location finding result. A framework would provide the structural prerequisites to divide the location finding problem into modules that provide a holistic assessment as combination of conventional and new approaches in location finding. 


\section{Conclusion}

This work aimed at the comparison of established conventional indicator sets and assessment methods for facility locations to new approaches focusing sustainability aspects. The comparison showed that conventional approaches support a more qualitative assessment. However, a weakness of conventional approaches is identified in the assumption of a static location environment, not accounting for real complexity. The missing analysis of influences from a volatile factory environment was identified as problematic. The main strength of existing sustainability-oriented approaches was identified in quantification. However, the applicability of quantitative methods in dynamic and complex systems must be examined in future research.

To conclude the results and existing research gaps, the discussion ends up with the recommendation, that existing approaches should be combined aiming at a minimization of future risks and an increase of facility location quality. A possible solution was identified in the development of a framework for combining the approaches and giving a structural concept for the holistic assessment by problem partition.

\section{References}

[1] Chen, L., Olhager, J., Tang, O.: Manufacturing facility location and sustainability: A literature review and research agenda. International Journal of Production Economics, 154-163 (2014)

[2] Terouhid, S.A., Ries, R., Fard, M.M.: Towards Sustainable Facility Location - A Literature Review. Journal of Sustainable Development, 18-34 (June 2012)

[3] Dombrowski, U., Ernst, S., Riechel, C.: Methodenframework der Fabrikplanung (MeFa). wt Werkstattstechnik online 104 4(104), 197-201 (2014)

[4] UN United Nations, Our common future, United Nations (1987)

[5] Sala, S., Farioli, F., Zamagni, A.: Progress in sustainability science: lessons learnt from current methodologies for sustainability assessment: Part 1. International Journal Life Cycle Assess, 1653-1672 (November 2013)

[6] Singh, R.K., Murty, H., Gupta, S., Dikshit, A.: An overview of sustainability assessment methodologies. Ecological Indicators, 281-299 (April 2012)

[7] Cloquell-Ballester, V.-A., Cloquell-Ballester, V.-A.: Monter de-Díaz, R., SantamarinaSiurana, M.-C.: Indicators validation for the improvement of environmental and social impact quantitative assessment. Environmental Impact Assessment Review, 79-105 (January 2006)

[8] Chen, D., Schudeleit, T., Posselt, G., Thiede, S.: A State-of-the-art Review and Evaluation of Tools for Factory Sustainability Assessment. Procedia CIRP, 85-90 (2013)

[9] Labuschagne, C., Brent, A.C., van Erck, R.P.G.: Assessing the sustainability performance of industries, pp. 373-385 (2005)

[10] U. U. N. D. f. S. Development, Indicators of sustainable development: Guidelines and Methodologies,

http: / / www . un.org/esa/sustdev/publications / indisd-mg2001.pdf

[11] Spangenberg, J.H., Pfahl, S., Deller, K.: Towards indicators for institutional sustainability: lessons from an analysis of Agenda 21. Ecological Indicators 2, 61-77 (2002) 
[12] Strohm, O., Ulich, E.: Integral Analysis and Evaluation of Enterprises: A Multilevel Approach in Terms of People, Technology, and Organization. Human Factors and Ergonomics in Manufacturing 8(3), 233-250 (1998)

[13] Kettner, H., Schmidt, J., Greim, H.-R.: Leitfaden der systematischen Fabrikplanung. Carl Hanser Verlag, Hannover (1984)

[14] Aggteleky, B.: Fabrikplanung - Band 1. Carl Hanser Verlag, Wien (1987)

[15] Wiendahl, H.-P., Reichardt, J., Nyhuis, P.: Handbuch Fabrikplanung. Carl Hanser Verlag, Hannover (2009)

[16] Pawellek, G.: Ganzheitliche Fabrikplanung - Grundlagen, Vorgehensweise, EDVUnterstützung. Springer, Hamburg-Harburg (2008)

[17] Eagan, P.D., Joeres, E.: Development of a facility-based environmental performance indicator related to sustainable development. Journal of Cleaner Production, 269-278 (1997)

[18] Corbière-Nicollier, T., Blanc, I., Erkman, S.: Towards a global criteria based framework for the sustainability assessment of bioethanol supply chains Application to the Swiss dilemma: Is local produced bioethanol more sustainable than bioethanol imported from Brazil? Ecological Indicators, 1447-1458 (September 2011)

[19] Reich-Weiser, C., Dornfeld, D.: A discussion of greenhouse gas emission tradeoffs and water scarcity within the supply chain. Journal of Manufacturing Systems, 23-27 (2009)

[20] Schenk, M., Wirth, S.: Fabrikplanung und Fabrikbetrieb - Methoden für die wandlungsfähige und vernetzte Fabrik. Springer, Chemnitz (2004) 